Original Article

\title{
The effect of pulsating electrostatic field application on the development of delayed onset of muscle soreness (DOMS) symptoms after eccentric exercise
}

\author{
Hannes Gatterer ${ }^{1)^{*}}$, Philippe Peters ${ }^{1)}$, Marc Philippe ${ }^{1)}$, Martin Burtscher ${ }^{1)}$ \\ 1) Department of Sport Science, University of Innsbruck: Fürstenweg 185, A-6020 Innsbruck, Austria
}

\begin{abstract}
Purpose] The aim of the study was to establish whether pulsating electrostatic field application, shown to increase blood flow and metabolic activity and to function as an ion pump, is able to reduce muscle pain after exercise-induced muscle damage. [Subjects and Methods] Seven participants (4 males, 3 females) performed two sessions of downhill running separated by at least 4 weeks. After the running sessions, participants were either treated for $45 \mathrm{~min}$ with a pulsating electrostatic field (field intensity, $9000 \mathrm{~V}$; current, $<9 \mathrm{~mA}$; frequency, $50 \mathrm{~Hz}$ ) or a sham treatment. The order of the intervention was random, and the condition was blinded for the participants. Muscle soreness score, creatine kinase, and jump ability were assessed before and up to 48 hours after running. [Results] Twenty-four and 48 hours after the downhill running, the muscle soreness score tended to be less increased after pulsating electrostatic field administration when compared with the sham setting (changes in muscle soreness score: $3.7 \pm 1.6$ vs. $5.7 \pm 2.2$ after $24 \mathrm{~h}$ and $3.1 \pm 2.0$ vs. $5.4 \pm 3.2$ after $48 \mathrm{~h}$, respectively). No further differences were detected. [Conclusion] The outcomes show that a pulsating electrostatic field might be a promising treatment to reduce muscle soreness after exercise-induced muscle damage. However, further studies are needed to confirm the present outcomes and to establish the mechanism by which a pulsating electrostatic field may reduce muscle pain. Key words: Exercise-induced muscle damage, Recovery, Downhill running
\end{abstract}

(This article was submitted May 22, 2015, and was accepted Jul. 9, 2015)

\section{INTRODUCTION}

Eccentric exercise was shown to provoke skeletal muscle damage leading to delayed onset of muscle soreness (DOMS $)^{1-3)}$. Acute muscle damage can cause discomfort at the site of injury, inflammation, oxidative stress, edema, and loss of muscular function and strength ${ }^{4,5}$. Many researchers have attempted to ameliorate symptoms by various treatments, such as nutritional interventions ${ }^{3,6)}$, pharmacological interventions ${ }^{7}$, massage $^{8-10)}$, low-intensity exercise ${ }^{10)}$, ultrasound application ${ }^{11)}$, or cryotherapy ${ }^{12)}$. Even though some positive effects have been reported, several studies did not find any reductions in the symptoms of muscle injuries.

Beside these treatments, static or pulsed electromagnetic field therapy have been used for the treatment of DOMS $^{13-15)}$. Again, some authors reported positive effects on DOMS symptoms, whereas others were not able to find benefits ${ }^{13,14)}$. Application of a pulsating electrostatic field (PESF), which is a comparable but not identical technique, might be a further method capable of reducing the symptoms of muscle soreness. A PESF was shown to increase vasomo-

\section{*Corresponding author. Hannes Gatterer (E-mail: hannes.} gatterer@uibk.ac.at)

(C2015 The Society of Physical Therapy Science. Published by IPEC Inc. This is an open-access article distributed under the terms of the Creative Commons Attribution Non-Commercial No Derivatives (by-ncnd) License $<$ http://creativecommons.org/licenses/by-nc-nd/3.0/>. tion and as a consequence blood flow ${ }^{16)}$, to reduce the formation of rouleaux, and to increase metabolic activity ${ }^{16,17)}$. Furthermore, a PESF may function as an ion pump able to move calcium ions, the concentration of which was shown to be increased after eccentric exercise with detrimental effects $^{2,18)}$. Due to these effects, it might be speculated that a PESF could prevent the development of DOMS and muscle strength loss after muscle damaging exercise. Therefore, the aim of the present study was to investigate the effect of PESF application on sensation of muscle soreness and muscle strength after eccentric exercise.

\section{SUBJECTS AND METHODS}

Nine sport students (5 males, 4 females) without any medical problems and not adapted to eccentric exercise were recruited for the study. All of them were informed about the study aims and gave written informed consent for participation. Two participants (one male and one female) had to be excluded from the final analysis, one because of a pre-start muscle soreness score of already 4 and one because of a pre-start CK value of $333 \mathrm{U} / \mathrm{L}$. Therefore, 7 participants (4 males and 3 females; weight, height, and age: $74.3 \pm 5.7 \mathrm{~kg}$ and $71.0 \pm 5.3 \mathrm{~kg}, 183.0 \pm 9.9 \mathrm{~cm}$ and $172.3 \pm 6.4 \mathrm{~cm}$, and $26.5 \pm 2.4$ years and $24.3 \pm 1.2$ years, respectively) were included in the final analysis. The study was carried out in conformity with the ethical standards of the declaration of Helsinki and was approved by Institutional Review Board of the Department of Sport Science, University of Innsbruck. 
Table 1. Values for jump height, creatine kinase, and muscle soreness score in the courses of the PESF and sham treatments

\begin{tabular}{|c|c|c|c|c|c|c|c|c|c|c|}
\hline & & Pre & After run & $\Delta$ & After $45 \mathrm{~min}$ & $\Delta$ & $\begin{array}{c}24 \mathrm{~h} \\
\text { After }\end{array}$ & $\Delta$ & $\begin{array}{l}48 \mathrm{~h} \\
\text { After }\end{array}$ & $\Delta$ \\
\hline Jump and & PESF & $276.2 \pm 8.7$ & & & $273.0 \pm 7.0$ & $-3.3 \pm 3.9$ & & & $273.0 \pm 10.5$ & $-3.3 \pm 3.6$ \\
\hline $\operatorname{reach}(\mathrm{cm})$ & Sham & $276.5 \pm 21.6$ & & & $272.0 \pm 23.5$ & $-4.5 \pm 5.3$ & & & $272.0 \pm 23.2$ & $-4.5 \pm 6.2$ \\
\hline Creatine & PESF & $133.6 \pm 32.1$ & & & & & & & $171.9 \pm 71.3$ & $38.3 \pm 58.7$ \\
\hline kinase $(\mathrm{U} / \mathrm{L})$ & Sham & $100.1 \pm 41.0$ & & & & & & & $271.7 \pm 274.5$ & $171.6 \pm 285.8$ \\
\hline Muscle & PESF & $1.4 \pm 1.4$ & $3.6 \pm 1.7$ & $2.1 \pm 2.0$ & $4.0 \pm 2.0$ & $2.6 \pm 1.6$ & $5.1 \pm 0.9$ & $3.7 \pm 1.6^{\mathrm{t}}$ & $4.6 \pm 1.5$ & $3.1 \pm 2.0^{t}$ \\
\hline soreness score & Sham & $1.0 \pm 1.0$ & $4.0 \pm 1.4$ & $3.0 \pm 1.7$ & $4.1 \pm 1.7$ & $3.1 \pm 2.2$ & $6.7 \pm 1.7$ & $5.7 \pm 2.2$ & $6.4 \pm 2.4$ & $5.4 \pm 3.2$ \\
\hline
\end{tabular}

PESF: pulsating electrostatic field

The table represents values of the same participants receiving the PESF and sham treatments ( $\mathrm{n}=7$, crossover design).

${ }^{t}$ There was a trend toward significant differences in delta values ( $\Delta=$ after values (i.e. $45 \mathrm{~min}, 24 \mathrm{~h}$, and $48 \mathrm{~h}$ after) minus pre value) between treatments (PESF vs. sham).

The study was designed as a single-blinded, placebocontrolled cross-over intervention study. All participants performed 2 downhill running sessions on a treadmill separated by at least 4 weeks. Before and at different time points after the sessions, muscle soreness score, creatine kinase (CK), and jump ability were assessed as described in detail below. The first running session was carried out in a slightly modified form according to Kingsley et $\mathrm{al}^{5 \text { ) }}$. Running sessions started with a 3 min stage of horizontal running at $5 \mathrm{~km} / \mathrm{h}$ (warm-up). Thereafter, the inclination was set at $-17.5 \%$, and the speed was increased every minute by $1 \mathrm{~km} / \mathrm{h}$ until reaching approximately $70 \%$ of the age-predicted maximal heart rate (HR) (calculated as 220 - age). This speed was kept constant until the end of the running session. Overall, the running duration was 30 minutes, not including the warm-up time. During the second test, the speed was regulated in the same way as during test one but independent of HR in order to have identical test speeds and a comparable muscular stimulus. Immediately after each run, half of the subjects were treated in a sitting position with a PESF for $45 \mathrm{~min}$, and half of the subjects were exposed to a sham treatment. After at least 4 weeks, in which participants were advised not to change their physical activity habits, the subjects that were treated with a PESF during the first session received the sham treatment and those that were treated with the sham treatment during the first session received the PESF treatment. The allocation to the treatment or placebo session was random. The (negative) PESF was generated with a New Health 9000 device (Akern srl, Pontassieve, Italy) and was applied through a mat with a field intensity of $9000 \mathrm{~V}$, a current of $<9 \mathrm{~mA}$, and a pulsatile frequency of $50 \mathrm{~Hz}$. The electrostatic field was confined to the ion mat surface, and it has been proven to be safe ${ }^{17)}$.

The general rating of muscle soreness was assessed as described by Trombold et al. ${ }^{3)}$ before and immediately after the runs, immediately after the $45 \mathrm{~min}$ treatment or sham treatment, and 48 hours after treatment. Participants subjectively rated the degree of soreness using a visual analog scale of 0 to 10 , with 0 describing "no soreness" and 10 describing "unbearable soreness". Jump ability (jump and reach test) was assessed before running, after the $45 \mathrm{~min}$ session, and 48 hours after the running. CK activity was assessed before running and 48 hours after running from capillary blood samples with a Reflotron Sprint device (Reflotron Sprint, Mannheim, Germany; reference range for men: 24-195 U/L at a measurement temperature of $37^{\circ} \mathrm{C}$ ).

Data were analyzed using PASW Statistic 18. Delta values $(\Delta)$ were calculated as post values (at different time points) minus pre values for both the PESF application and sham setting. Differences at baseline, changes in the course of PESF or sham treatment, and differences between conditions ( $\Delta$ values for the PESF and sham treatment) were assessed by paired Student's t-tests or the Wilcoxon test as appropriate. Spearman correlation analyses were used to calculate associations between CK and CMJ changes and muscle soreness score. Data are presented as means \pm SD. The level of significance was set at $p \leq 0.05$.

\section{RESULTS}

Values before the two sessions did not differ $(\mathrm{p}<0.05)$. When compared with the pre values, the muscle soreness score was increased at all time points and under both conditions $(\mathrm{p}<0.05)$. Jump performance was reduced immediately after the sham application $(\mathrm{p}=0.038)$ and tended to be reduced immediately after the PESF application $(\mathrm{p}=0.054)$. Table 1 shows values for $\mathrm{CK}$, muscle soreness score, and jump height in the courses of the PESF and sham treatments. Twenty-four and 48 hours after downhill running, the muscle soreness score (MSS) tended to be less after PESF administration when compared with the sham treatment ( $\triangle$ MSS: $3.7 \pm 1.6$ vs. $5.7 \pm 2.2$ after $24 \mathrm{~h}$ and $3.1 \pm 2.0$ vs. $5.4 \pm 3.2$ after $48 \mathrm{~h}$, respectively; $0.05<\mathrm{p}<0.01$ ). Furthermore, the highest muscle soreness scores were found after the sham session, with one subject having a score of 9 and two subjects having a score of 8 after 24 hours. After $48 \mathrm{~h}$, one subject had a score of 10 , one subject had a score of 9 , and one subject had a score of 7 . No subjects had scores $>6$ at 24 hours after the treatment session. After 48 hours, one subject had a score of 7, whereas all others had lower values. No further differences were detected, and no significant associations were found.

\section{DISCUSSION}

The main finding of the present investigation was that PESF application tended to reduce muscle soreness scores without significantly affecting CK increase and jump performance decrease.

To the best of our knowledge, this is the first study to use 
a PESF after downhill running for the prevention of muscle soreness. In the literature, different methods, including cold or infrared therapy, massage, pharmacological intervention, etc., have been applied to reduce muscle pain after eccentric exercise $^{7,8,10,12)}$. The mechanisms causing beneficial effects are as diverse as the methods applied. For cold application, the main beneficial effect is thought to be the cold-related vasoconstriction, which may limit vessel permeability and thus inflammatory processes ${ }^{12)}$. The mechanism by which infrared therapies might induce potential positive effects is mainly based on the increased peripheral flow due to warmth-related vasodilatation, which could enhance the evacuation of edema, limiting inflammation and perceived pain $^{12)}$. The mechanisms mediating the biological benefits of nutritional interventions are not clear but may be linked to the attenuation of oxidative stress and inflammation ${ }^{3)}$. With respect to electromagnetic field therapy, it was suggested that the treatment influences muscle immune and inflammatory responses by an unknown mechanism, may disrupt afferent input from free nerve endings of nociceptors, and may influence excitation-contraction coupling processes ${ }^{13,15,19)}$. In the present study, PESF application might have induced similar effects. Additionally, the improvement of vasomotor performance might have provoked some beneficial effects ${ }^{16,17)}$. Comparable to the effects of infrared application, the increased blood flow might have enhanced the removal of edema, limited the inflammatory response, and reduced perception of pain ${ }^{12}$. A further mechanism might be the function of a PESF as an ion pump moving positively charged ions, e.g., calcium and hydrogen ${ }^{16}$. The calcium concentration was shown to be elevated in skeletal muscle cells following eccentric contractions ${ }^{18}$. Increased calcium concentrations within the sarcoplasm have the potential to activate many different molecular pathways in skeletal muscle, including the phospholipase-prostaglandin pathway and the calpain proteolytic pathway, which might lead to breakdown of the cell membrane and myofibrils ${ }^{2)}$. However, whether or not such mechanisms might be involved in processes of recovery from exercise-induced muscle damage still needs to be determined. It has to be mentioned that although there was a trend toward a decrease in muscle soreness score, CK and jump performance did not seem to be affected by PESF application. In this regard, the small sample size certainly is a main limitation of the present study and outlines its nature as a pilot study. Nonetheless, when looking at the MSS and CK values in Table 1, some beneficial effects clearly seem to be apparent. This is supported by the finding that the highest MSS values were found after the sham treatment. Additionally, PESF application for only 45 min may be considered a short exposure time, and it is not known if a longer PESF application time would have been more effective.

In conclusion, application of a PESF might be a promising treatment to reduce muscle soreness after exercise-induced muscle damage. However, further studies are needed to confirm the present outcomes and to establish the mechanism by which a PESF may reduce muscle pain.

\section{REFERENCES}

1) Eston RG, Mickleborough J, Baltzopoulos V: Eccentric activation and muscle damage: biomechanical and physiological considerations during downhill running. Br J Sports Med, 1995, 29: 89-94. [Medline] [CrossRef]

2) McKune A, Semple S, Peters-Futre E: Acute exercise-induced muscle injury. Biol Sport, 2012, 29: 3-10. [CrossRef]

3) Trombold JR, Barnes JN, Critchley L, et al.: Ellagitannin consumption improves strength recovery $2-3 \mathrm{~d}$ after eccentric exercise. Med Sci Sports Exerc, 2010, 42: 493-498. [Medline] [CrossRef]

4) Braun WA, Dutto DJ: The effects of a single bout of downhill running and ensuing delayed onset of muscle soreness on running economy performed 48 h later. Eur J Appl Physiol, 2003, 90: 29-34. [Medline] [CrossRef]

5) Kingsley MI, Kilduff LP, McEneny J, et al.: Phosphatidylserine supplementation and recovery following downhill running. Med Sci Sports Exerc, 2006, 38: 1617-1625. [Medline] [CrossRef]

6) Beaton LJ, Allan DA, Tarnopolsky MA, et al.: Contraction-induced muscle damage is unaffected by vitamin E supplementation. Med Sci Sports Exerc, 2002, 34: 798-805. [Medline] [CrossRef]

7) Sayers SP, Knight CA, Clarkson PM, et al.: Effect of ketoprofen on muscle function and sEMG activity after eccentric exercise. Med Sci Sports Exerc, 2001, 33: 702-710. [Medline] [CrossRef]

8) Frey Law LA, Evans S, Knudtson J, et al.: Massage reduces pain perception and hyperalgesia in experimental muscle pain: a randomized, controlled trial. J Pain, 2008, 9: 714-721. [Medline] [CrossRef]

9) Gatterer H, Schenk K, Wille M, et al.: Effects of massage under hypoxic conditions on exercise-induced muscle damage and physical strain indices in professional soccer players. Biol Sport, 2013, 30: 81-83. [Medline] [CrossRef]

10) Martin V, Millet GY, Lattier G, et al.: Effects of recovery modes after knee extensor muscles eccentric contractions. Med Sci Sports Exerc, 2004, 36: 1907-1915. [Medline] [CrossRef]

11) Kim SK, Kim MC: The affect on delayed onset muscle soreness recovery for ultrasound with bee venom. J Phys Ther Sci, 2014, 26: 1419-1421. [Medline] [CrossRef]

12) Hausswirth C, Louis J, Bieuzen F, et al.: Effects of whole-body cryotherapy vs. far-infrared vs. passive modalities on recovery from exerciseinduced muscle damage in highly-trained runners. PLoS ONE, 2011, 6: e27749. [Medline] [CrossRef]

13) Jeon HS, Kang SY, Park JH, et al.: Effects of pulsed electromagnetic field therapy on delayed-onset muscle soreness in biceps brachii. Phys Ther Sport, 2015, 16: 34-39. [Medline] [CrossRef]

14) Reeser JC, Smith DT, Fischer V, et al.: Static magnetic fields neither prevent nor diminish symptoms and signs of delayed onset muscle soreness. Arch Phys Med Rehabil, 2005, 86: 565-570. [Medline] [CrossRef]

15) Walsh J, Simonds L, Tiidus PM: Pulsed-magnetic field therapy does not influence indices of muscle damage following eccentric exercise: a preliminary study. Med Sportiva, 2010, 14: 199-203. [CrossRef]

16) De Lorenzo A, Martinoli R, Carbonelli MG, et al.: Resting metabolic rate incremented by pulsating electrostatic field (PESF) therapy. Diabetes Nutr Metab, 2004, 17: 309-312. [Medline]

17) Liani M, Trabassi E, Cusaro C, et al.: Effects of a pulsatile electrostatic field on ischemic injury to the diabetic foot: evaluation of refractory ulcers. Prim Care Diabetes, 2014, 8: 244-249. [Medline] [CrossRef]

18) Duan C, Delp MD, Hayes DA, et al.: Rat skeletal muscle mitochondrial $[\mathrm{Ca} 2+]$ and injury from downhill walking. J Appl Physiol 1985, 1990, 68: 1241-1251. [Medline]

19) Weintraub MI, Wolfe GI, Barohn RA, et al. Magnetic Research Group: Static magnetic field therapy for symptomatic diabetic neuropathy: a randomized, double-blind, placebo-controlled trial. Arch Phys Med Rehabil, 2003, 84: 736-746. [Medline] [CrossRef] 